\title{
Two cases of primary oxalosis
}

\author{
J. W. KOTEN, C. van GASTEL, E. J. DORHOUT MEES, L. W. J. HOLLEMAN, \\ AND R. D. SCHUILING \\ From the Institute of Pathology, Rijksuniversiteit, Utrecht, The Netherlands
}

SYNOPSIS Two patients, aged 66 and 62 years, are described who suffered from unilateral anuria and contralateral stone formation due to primary oxalosis. The diagnosis was established by microscopical examination of necropsy material in the first patient and by renal biopsy in the second and was confirmed by chemical and $x$-ray investigation of tissues and calculi. The sequence of events leading to the rather sudden precipitation of oxalate in the tissues is discussed, and a tentative explanation for the unilateral anuria is offered.

\section{CASE 1}

A 66-year old stock farmer was admitted to the hospital on 6 March 1963, with complaints of lassitude, dyspnoea, pallor, shooting pains in the legs, and dysuria. He had been in good health until 1947, when an operation for left-sided kidney stones was performed. Since that time he had occasionally suffered from renal colic, haematuria, and passage of grit with the urine.

His two daughters, brother, and sister were healthy; his mother had died of a stroke. In 1961 a medical examination showed a slight proteinuria and a normal plasma urea level of $15 \mathrm{mg} . / 100 \mathrm{ml}$. The patient was a pale man with a deep, sighing respiration. Blood pressure was $130 / 80 \mathrm{~mm}$. Hg. The temperature was normal. The tongue was dry and there was a stomatitis. The examination of heart, lungs, and abdomen did not show any abnormalities. Below the groins no pulsation of the arteries of the legs could be felt, while the oscillometer showed only minimal excursions.

The daily volume of urine was $350-700 \mathrm{ml}$, with a proteinuria of $2.5 \%$. The sediment contained erythrocytes and a few leucocytes but no crystals. Culture showed enterococcus $2 \cdot 10^{4}$ per $\mathrm{ml}$. Haemoglobin was 8.9 g. $/ 100$ ml., R.B.C.s $2,800,000$, W.B.C.s 13,100 , E.S.R. $45 \mathrm{~mm}$. after one hour; urea $640 \mathrm{mg} . / 100 \mathrm{ml}$,, creatinine $35 \mathrm{mg} . / 100 \mathrm{ml}$., Na $124 \mathrm{mEq} . / 1 ., \mathrm{K} 7 \cdot 3 \mathrm{mEq} . / \mathrm{l}$,, Cl $91 \mathrm{mEq} . / \mathrm{l}$, bicarbonate $4.8 \mathrm{mEq} . / 1$. ., Ca $4.0 \mathrm{mEq} . / \mathrm{l}$., P $9.1 \mathrm{mEq} . / \mathrm{l}$. , uric acid $9.4 \mathrm{mg} . / 100 \mathrm{ml}$., alkaline phosphatase 3.6 units $/ 100 \mathrm{ml}$. (King and Armstrong method).

The electrocardiogram showed small $R$-waves in lead $V_{2}$. A calculus in the left kidney was visible on the radiograph of the abdomen.

Cystoscopic examination showed that there was no urine flow from the right ureter. On retrograde pyelography a nearby normal ureter and pelvis were visible on both sides, but the left pelvis contained a stone.

After treatment with intravenous blood and bicarbonate infusions, penicillin, and peritoneal dialysis, the patient showed only temporary improvement. On 16

Received for publication 10 July 1964.
March 1963 an ischaemic necrosis of the feet developed. The patient died in a uraemic coma.

The condition was tentatively diagnosed as uraemia of unknown origin with a pelvic stone in the left kidney and multiple arteriosclerotic occlusions of the arteries of the right kidney and the legs. Moreover there were signs of an old myocardial infarct.

\section{PATHOLOGICAL FINDINGS IN CASE 1}

Necropsy revealed a regularly built, well-nourished man with oedema of the legs and scrotum. There was a bluish discoloration of the dorsal part of the feet. The heart $(500 \mathrm{~g}$.) showed a grey, firm patch in the left posterior wall. The thickness of the left ventricular wall was 20 to $22 \mathrm{~mm}$., that of the right ventricular wall 4 to $7 \mathrm{~mm}$. Obstruction was found neither in the coronary nor in the pelvic arteries; there was no opportunity to examine the arteries of the legs. The arteries in general showed only very few arteriosclerotic lesions. The kidneys were (weight, R 120 g., L 140 g.) contracted. The capsule was slightly adherent and the surface granular. Cutting produced a grinding sound. The surface of the cut showed an equal shrinkage of cortex and medulla. The cortex of the left kidney had a thickness of 7 to $10 \mathrm{~mm}$. The wall of the pelvis was thickened and it contained many round, coralline, and tetrahedral stones. The cortex of the right kidney had a thickness of 4 to $6 \mathrm{~mm}$., and the marking had faded. The pelvis contained some grit and concrements the size of hailstones. There was some purulent mucus in the bronchi. The liver $(1,700$ g.) and spleen $(160$ g.) were normal. The scar of a peptic ulcer was visible in the stomach.

MICROSCOPICAL EXAMINATION Both kidneys contained numerous birefringent crystals in radial arrangement, mostly in the form of rosettes or 
sheaves. The average size of the crystals was $25 \mu$. They were yellow and morphologically identical with the description given in other cases of oxalosis. If appropriately stained, P.A.S.-positive material was observed at the surface of the crystals and sometimes in concentric rings within them. Due to the alteration in the tubular cells, caused by the crystals, it was difficult to localize them exactly. Most of the crystals were deposited in the proximal tubules. Crystalline material was found also between the atrophic epithelial cells and the basement membrane, which was thickened at several places. This crystalline material occasionally protruded like a mushroom into the lumen. Around those tubules, which had lost their epithelial cells, the P.A.S. stain revealed an intact basement membrane. The distal tubules were atrophic. A slight hydropic degeneration was found in some epithelial cells. The collecting tubules contained only a few crystals. The interstitial tissue contained crystalline material also, especially in the fibrotic areas. In addition there were some inflammatory foci. No crystals were found in the glomeruli, many of which were hyalinized. A marked difference between the two kidneys was noted: the picture of a

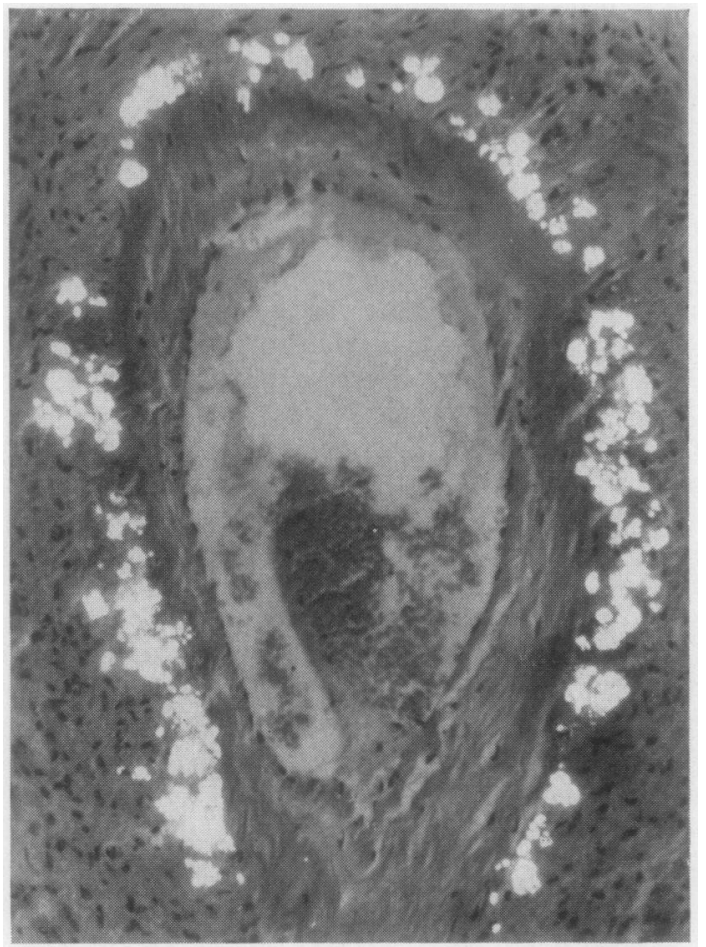

FIG. 2. Calcium oxalate crystals in a medium-sized artery of the prostate of case 1 (haematoxylin and ensin half-crossed Nicol prisms). pyelonephritis predominated in the left, whereas the right one contained more oxalate and showed an extensive fibrosis.

The myocardium showed a profuse fibrosis and the firm patch in the left posterior wall consisted mainly of fibrous tissue. There was much oxalate, especially in the fibrotic areas. The oxalate crystals were localized both in the muscle fibres and in the connective tissue. In the arteries oxalate was found between the tunica media and the lamina elastica interna; it protruded like a mushroom into the lumen. Arteries containing oxalate were found in the spleen, pancreas, lungs, adrenals, prostate (Fig. 2), striated muscle, and in the heart. In the bone a moderate amount of oxalate was found at the margins of the trabeculae; the marrow, however, contained but little oxalate. The blood cell formation seemed normal. A small amount of haemosiderin was present. The testes showed oxalate in the tubuli seminiferi and in the rete testis. As in the kidneys the localization of the crystals was intra-epithelial as well as subepithelial. There was some focal fibrosis. Little oxalate was found in the exocrine part of the pancreas. The spleen contained no oxalate, but much haemosiderin.

\section{CASE 2}

A 62-year-old postman was admitted on 30 March 1963. For the previous six months he had suffered from lassitude and once he had had a period of purulent bronchitis. His physician found proteinuria and referred him to another hospital. But for the passage of a stone the size of a pea four months before, there had never been symptoms indicating a kidney or urinary tract disease. His two sons, his brother and two sisters were reported to be in good health. One brother died of 'croup' at the age of 2 years. None of these relations had a history of renal stones or haematuria. The $x$-ray photograph showed a calculus in the right kidney and a remarkably dense left kidney shadow, without signs of calcification. The patient was referred to the University Hospital in Utrecht on a diagnosis of urinary tract infection and renal insufficiency.

On examination the patient was a slightly dehydrated, vomiting, pale man with deep respirations and a blood pressure of $145 / 75 \mathrm{~mm} . \mathrm{Hg}$. The temperature was normal. The daily volume of urine was 400 to $800 \mathrm{ml}$., with a proteinuria from slight to $4.7 \%$. The sediment was normal. Culture showed $E$. coli $>10^{6}$ per $100 \mathrm{ml}$., oxalate excretion $32 \mathrm{mg} / 24$ hour. The blood urea level was $455 \mathrm{mg} . / 100 \mathrm{ml}$., creatinine $43 \mathrm{mg} . / 100 \mathrm{ml}$, serum bicarbonate $3.7 \mathrm{mEq} . / \mathrm{l}$., uric acid $23 \mathrm{mg} . / 100 \mathrm{ml}$.

The electrocardiogram was within normal limits. After the introduction of ureteral catheters urine was only obtained from the right kidney. Retrograde examination revealed a non-functioning left kidney with a normal pelvis.

A needle biopsy of the left kidney was performed. The specimen consisted of a fragment of renal cortex with 
two Malpighian bodies. These glomeruli were normal, but there was a small crystal in one of the capillary loops. The capsular spaces were wide. Nearly all tubules were occupied by masses of crystals which were strongly birefringent. Only a few tubules did not contain crystalline deposits. The interstitial connective tissue was increased and chronically inflamed. The crystalline material could be dissolved in $1 \mathrm{~N}$-hydrochloric acid, but was resistant against treatment with $10 \%$ acetic acid, which strongly suggested the presence of calcium oxalate.

Treatment consisted of chloramphenicol, correction of the electrolyte pattern by peritoneal dialysis, and blood transfusions $(5 \times 450 \mathrm{ml}$.). The patient improved markedly and left hospital on 26 April 1963, although the creatinine clearance was still extremely low (1 ml./min.). Shortly afterwards he had to be re-admitted because of congestive heart failure, which was successfully treated. The blood pressure was now $200 / 115 \mathrm{~mm}$. Hg. The $\mathrm{Hb}$ was lowered to $5.2 \mathrm{~g} . / 100 \mathrm{ml}$., reticulocytes 33 and $85 \%$. In a bone marrow aspiration haemosiderin was found in the cells of the reticulo-endothelial system and there were a few sideroblasts. Ocular fundus examinaiions revealéd exudates and haemorrhages and moderate to marked sclerosis of the arterioles with irregular narrowing. This time the patient complained of pain in the legs. At the feet only the right arterial dorsalis pedis was palpable, while oscillometry showed hardly any excursions. Chemical analysis of the plasma showed urea $265 \mathrm{mg}$./ $100 \mathrm{ml}$., creatinine $32 \mathrm{mg} . / 100 \mathrm{ml}$., $\mathrm{Na} 135 \mathrm{mEq} . / \mathrm{l}$., K $7 \cdot 1 \mathrm{mEq} . / 1$., bicarbonate $18.8 \mathrm{mE} . q / 1$., Ca $2.4 \mathrm{mEq} . / 1$., P $9.1 \mathrm{mEq} . / 1$. An attempt to wash out some of the concrements by diuresis induced by mannitol was unsuccessful. On 6 June the patient became convulsive and died.

\section{PATHOLOGICAL FINDINGS IN CASE 2}

The body was that of a regularly built, well-nourished man with a pale skin and pale mucous membranes. There was oedema of the legs. The pericardium had a shaggy surface and contained $450 \mathrm{ml}$. fibrinous haemorrhagic exudate. The heart weighed $435 \mathrm{~g}$., and the myocardium and coronary arteries seemed to be normal. The left pleural cavity contained $1,000 \mathrm{ml}$. of a clear, yellow fluid, the right one $800 \mathrm{ml}$. The lungs were oedematous. The left kidney (weight

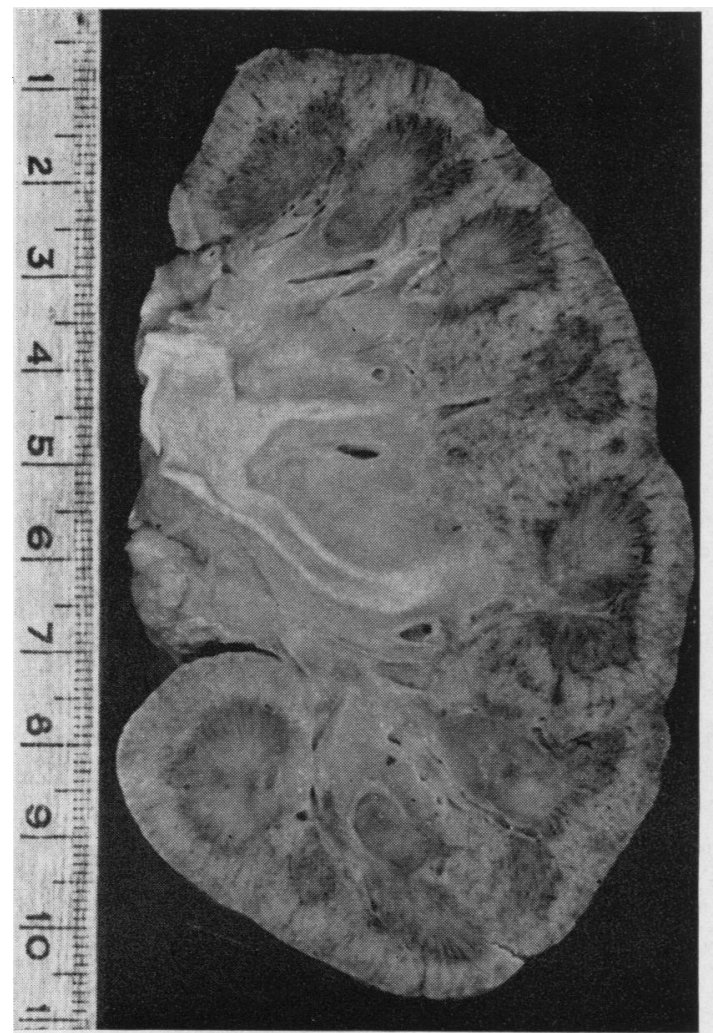

FIG. 1a.

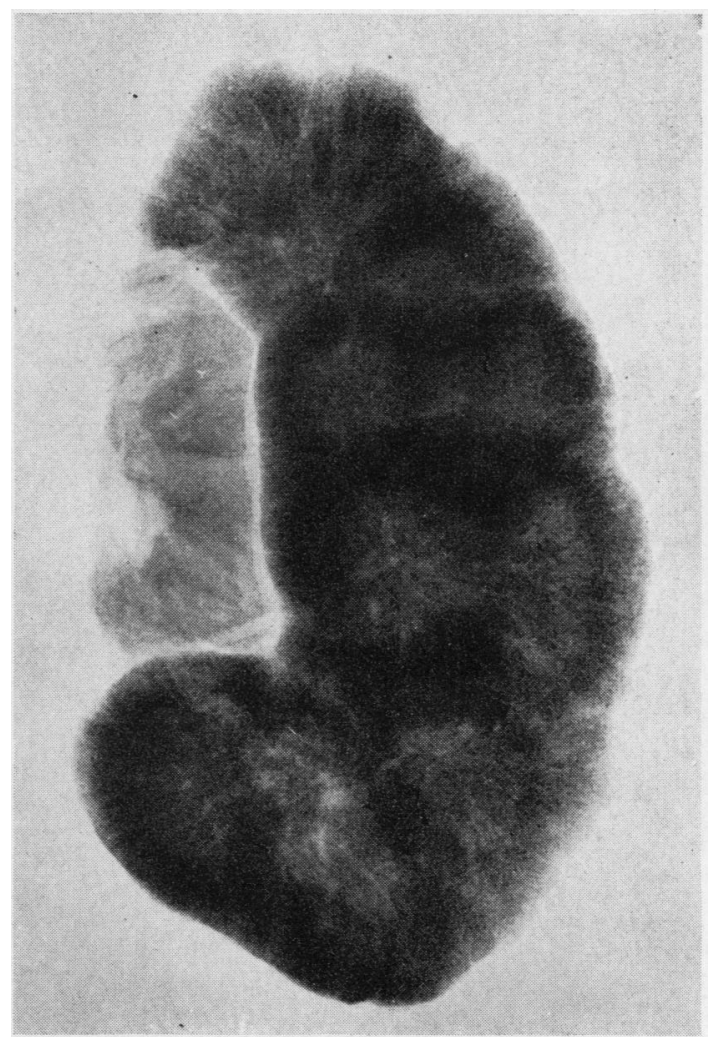

FIG. $1 \mathrm{~b}$.

FIG. 1a. Cut surface of the left kidney of case 2 (the scale is shown in $\mathrm{cm}$.).

FIG. 1b. Radiograph of a $5 \mathrm{~mm}$. slice of kidney tissue, adjacent to the surface shown in Figure la. 


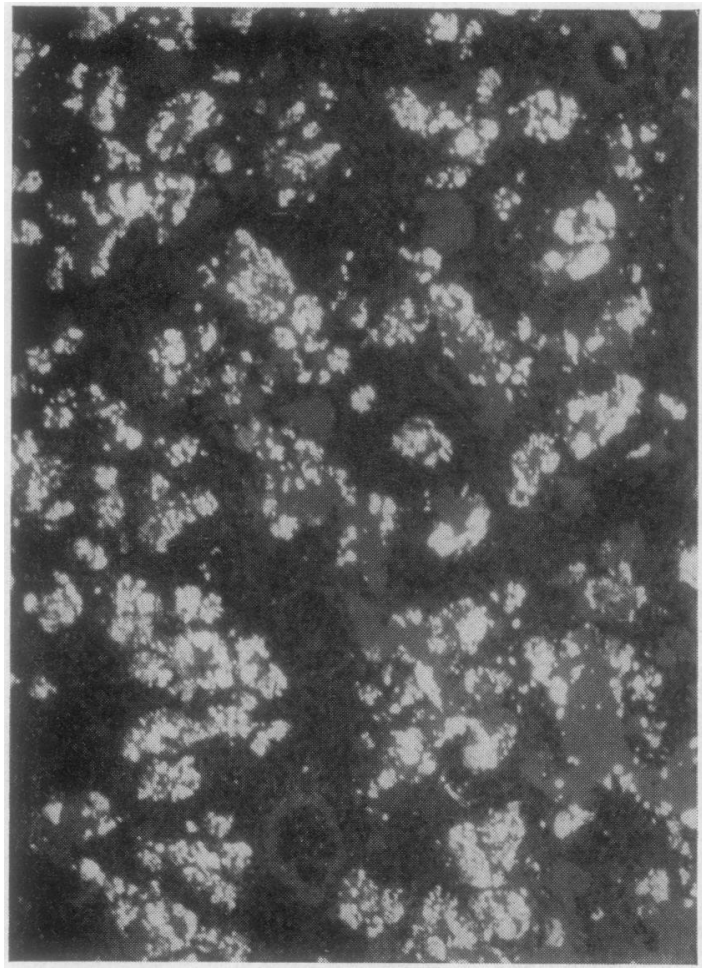

FIG. 3.

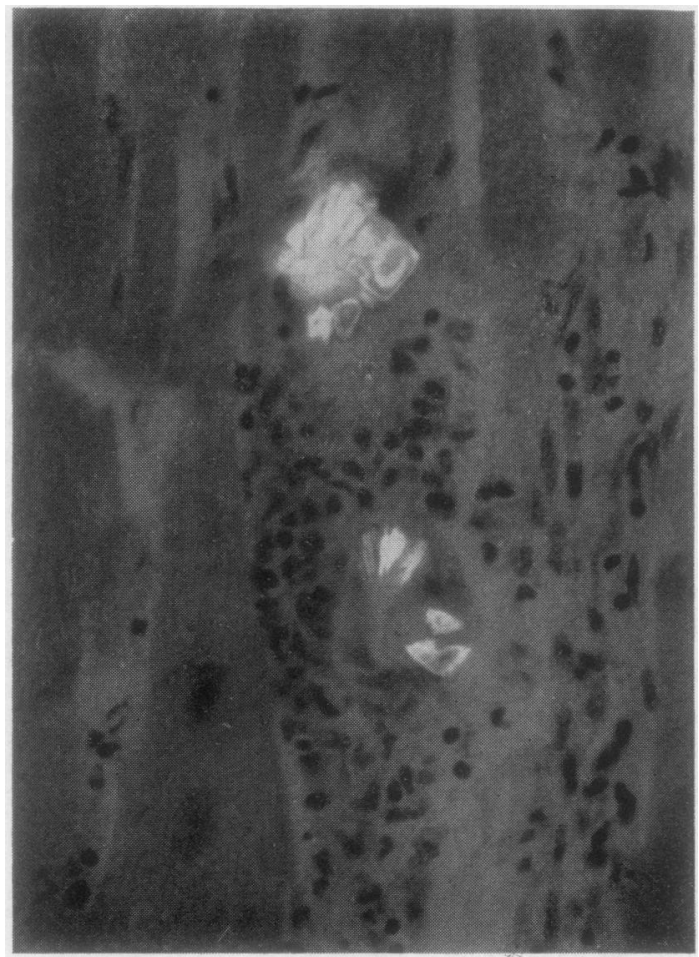

FIG. 5 .

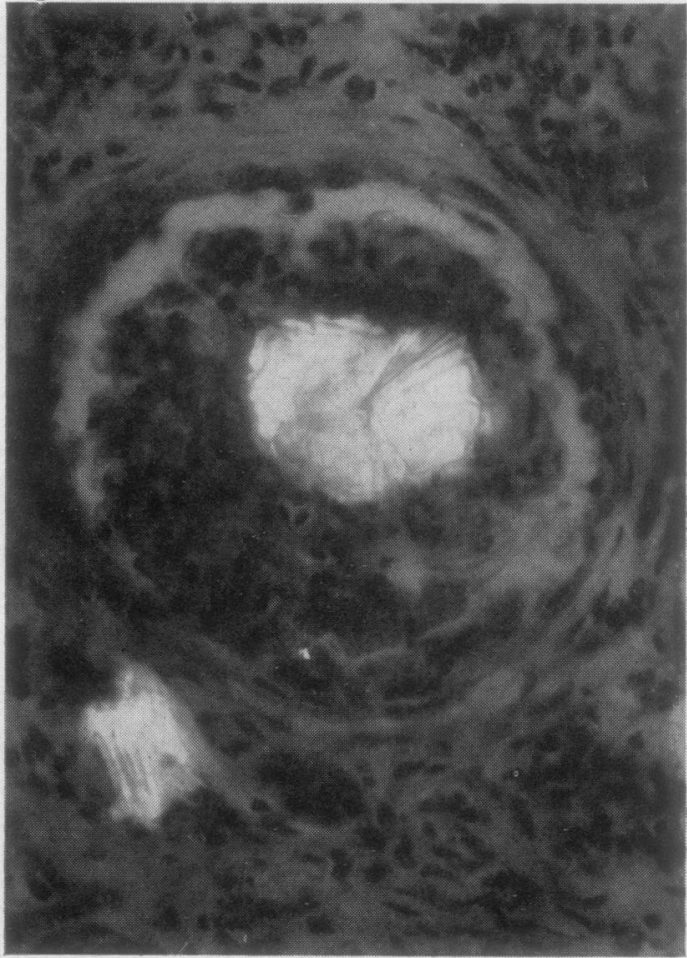

FIG. 4.

FIG. 3. Cortex of the left kidney of case 2, crowned by birefringent material (haematoxylin and eosin half-crossed Nicol prisms).

FIG. 4. Left kidney of case 2: calcium oxalate crystal in a glomerulus (haematoxylin and eosin half-crossed Nicol prisms).

FIG. 5. Myocardium of case 2: calcium oxalate crystals and inflammation with giant cells (haematoxylin and eosin half-crossed Nicol prisms). 
130 g.) and the capsule could be easily stripped off. The surface showed red patches and a fine yellow granularity. Cutting the kidney produced a grinding sound. The cortex showed $4 \mathrm{~mm}$. of thickness; the marking had faded. No stones were found in the pelvis (Fig. 1a). A radiograph of a slice of about $5 \mathrm{~mm}$. thickness adjacent to the cut surface shown in Fig. 1a reveals that the opaque area caused by the presence of the oxalate is mainly confined to the cortex. The right kidney weighed $80 \mathrm{~g}$. and looked similar, but showed coarser retractions of the surface. The cortex was only $2 \mathrm{~mm}$. thick and the marking had faded. The pelvis was dilated and had a thickened wall. It contained a nipple-shaped stone, which protruded into the mouth of the ureter.

MiCROSCOPICAL EXAMINATION Virtually the same characteristics were found as in case 1 . In the left kidney the proximal tubules contained much oxalate (Fig. 3). Some birefringent material was in the glomeruli (Fig. 4). Little oxalate was found in the distal and collecting tubules. In the tubules the localization of the crystals was mainly subepithelial and most of the epithelial cells had vanished. In the glomeruli the lesions were slight, except for some hyalinization of the tuft. The interstitium showed fibrosis, mononuclear cells, and some giant cells. The right kidney showed a picture of pyelonephritis with contraction and less oxalate. The microscopical findings and the localization of the crystals in other organs were also similar to those of case 1 . Besides the myocardial fibrosis and disposition of oxalate some small infiltrates of mononuclear cells and giant cells were found in the heart (Fig. 5). Oxalate crystals were also present in the aorta and in the arteries of the pancreas, lungs, liver, spleen, adrenals, prostate and seminal vesicles, in the rete testis and epididymis. Many crystals were found in the bone of the margins of the trabeculae. The marrow contained little oxalate; the blood cell formation seemed normal, but there was much haemosiderin present just as in the spleen. The three parathyroid glands showed the uniform picture of a lack of fat cells and a large increase of the number of gland cells, mainly chief cells of normal appearance. No mitoses were found. The arrangement of the gland cells was partly alveolar and partly in cords.

\section{CHEMICAL INVESTIGATION OF RENAL CALCULI AND TISSUE OBTAINED AFTER NECROPSY}

Qualitative analysis of the renal calculi proved that they consisted almost entirely of oxalate; the presence of carbonate could not be demonstrated and phosphate and urates were present in traces only. Consequently these calculi seem to be a specific entity, since oxalate calculi occurring in other pathological conditions usually contain distinct amounts of phosphate. The crystals in the renal and cardiac tissues were isolated from the tissue by homogenizing the material in a saturated solution of potassium carbonate followed by centrifugation. The organic tissue constituents form a compact layer at the surface of the liquid due to their lower specific gravity whereas the crystals are deposited at the bottom as an almost colourless sediment. A more complete separation was obtained by homogenizing the tissue in a $60 \%$ solution of chloral hydrax and heating at about $100 \mathrm{C}$. until most of the organic matter had been dissolved. The sediment obtained after centrifugation could be purified by repeated sedimentation from diluted acetic acid.

\section{CRYSTALLOGRAPHICAL IDENTIFICATION}

To ascertain the exact nature of the crystalline matter, an $x$-ray crystallographical determination was done, partly in situ in the original tissue, by the Debye-Scherrer powder method. By means of a special set-up (Guinier-de Wolff camera, constructed by Nonius, Delft) we were able to record simultaneously the $x$-ray diagrams of four

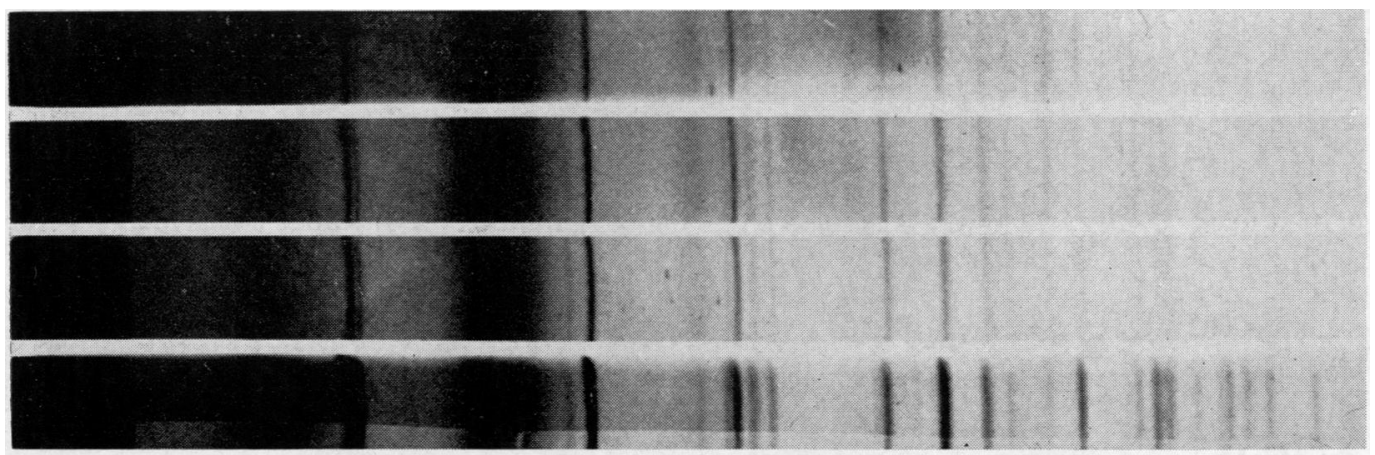

FIG. 6. Radiological diagrams of crystals, in ascending order: pure calcium oxalate monohydrate, section kidney case 2, crystalline residue of kidney case 1 after treatment with chloral hydrate, section kidney case 1. Note that the four samples give an identical pattern. 
different samples on one film. This procedure allowed a direct comparison of unknown samples with known standards. From each patient a section of about $2 \mathrm{~mm}$. thickness of the (non-calculous) kidneys (which were considered equivalent to powder samples) was mounted on the same sample holder. This was done at the same time with a sample of crystals isolated from kidney tissue of case 1 by treatment with chloral hydrate, and with a sample of chemically pure calcium oxalate monohydrate, $\mathrm{CaC}_{2} \mathrm{O}_{4} \cdot \mathrm{H}_{2} \mathrm{O}$. The four samples were identical within the limits of the method (Fig. 6), i.e., no crystalline substance other than calcium oxalate monohydrate can be present in amounts of more than $3 \%$ without detection on the photograph.

\section{DISCUSSION}

The deposition of appreciable quantities of calcium oxalate, which we demonstrated by various methods in the kidneys and the other tissues of our patients, led us to the diagnosis of primary oxalosis.

In view of the relatively rare occurrence of oxalosis of endogenous origin it was considered important to exclude any secondary cause, such as, for instance, ethylene glycol poisoning (Friedman, Greenberg, Merrill, and Dammin, 1962). Though the histological picture showed some hydropic degeneration of the kidney tubules, it was characterized by a more massive deposition of oxalate than is usually found in the latter condition.

Careful investigation of the history of both patients failed to reveal any indication of intoxication. In both cases the clinical course was not consistent with an acute intoxication either. Moreover the endogenous character of the condition in case 1 was made probable by the finding of an increased oxalate excretion in the patient's daughter (62 mg./24 hr., normal excretion $30 \mathrm{mg}$./24 hr.). The oxalate excretion in case 2 , though relatively high in view of his extremely diminished renal function, was within normal limits, as is found in most cases of primary oxalosis in the terminal phase.

Whereas many of the data reported here agree with former findings on primary oxalosis, a few particulars of the cases under consideration call for comment.

In case 2 the diagnosis was made when the patient was still alive. As far as we know this is the second case of a diagnosis of oxalosis which has been confirmed by a needle biopsy. The first case has been reported by Dérot, Legrain, Prunier, and Quénus (1962).

The age of the patients in both cases, 66 and 62, is remarkable in view of the prevailing opinion that oxalosis, being the result of an inborn error of metabolism, leads to death at an early age (Largiadér and Zollinger, 1960). About 20 of the 50 or so cases described in the literature were adults. The maximum age reported was 54 (Zollinger and Rosenmund, 1952).

Another remarkable feature of both cases is the accompanying haemosiderosis of the spleen and bone marrow. A similar finding has been reported by Largiadér (1960) in rats after administering oxalate for prolonged periods of time.

Regarding the localization of the oxalate crystals we found, as mentioned in the literature, that most of them were deposited in the proximal tubules. However, the occurrence of crystals in the glomeruli, as in case 2 , is unusual. The latter localization has been found in only three cases which were reported by Scowen, Stansfeld, and Watts (1959), Randerath, and Bohle (1959), and Godwin, Fowler, Dempsey, and Henneman (1958).

These findings can be understood in terms of a mechanism of the later stages of the oxalosis process, which we should like tentatively to put forward. It seems reasonable to suppose that the oxalate is primarily deposited in the epithelial cells of the tubules, and that this deposition is followed by degeneration and necrosis of these cells. The crystalline material then may enter the lumen causing obstruction. Sometimes the crystals seem to be localized in the interstitium, in contrast to observations by Brož, Šťovíček, and Štěpán (1957) who suppose that the crystals remain in the lumen of the tubules. In our cases only a few crystals were found in the distal and the collecting tubules. If present there, they were often localized subepithelially. The abundant deposition of oxalate crystals in the tubules explains the anuria in the non-calculous kidneys of our patients. In the other calculous kidney of each patient there was pyelonephritis and less oxalate was deposited.

It is noteworthy that the calculi in both cases combine variability of form with a remarkably constant chemical composition, all stones virtually consisting of pure calcium oxalate. In fact, attention was first drawn to the possibility of oxalosis, both by the observation of massive crystalline deposits in the kidneys at necropsy, and by the analysis of the calculi. The latter may form an essential element in the diagnosis, an observation which once more underlines the necessity of chemical analysis of every kidney stone.

The clinical and morphological pecularities of our patients give rise to some suggestions about the pathogenesis of the renal failure in oxalosis. The condition generally is considered as the terminal phase of primary hyperoxaluria. The latter, an inborn error of metabolism, is characterized by a continuously high endogenous formation of oxalate, which is subsequently excreted with the urine. 
In the terminal phase of primary hyperoxaluria the kidneys do not maintain the high excretion of oxalate (Scowen et al., 1959). This phenomenon is due to the destruction of kidney tissue and may explain why a primary hyperoxaluria decompensates at a certain moment. Renal function becomes impaired by the deposition of the oxalate in the tubules, the stone formation, and the complicating pyelonephritis. The diminishing excretion of oxalate leads to a rising blood level and deposition of oxalate in the tissues. It is evident that the calcium oxalate in the tissues is not inert since it causes inflammation and fibrosis of the renal parenchyma and the myocardium, probably by splitting off oxalic acid. In this way a vicious circle is established, which may lead to a fairly sudden rapid deterioration in the patient's condition, which happened in our two cases.

In this connexion it is noteworthy that in both cases one of the kidneys actually contained stones and was damaged by the complicating pyelonephritis, whereas on microscopical examination it showed appreciably less deposition of oxalate than the other. It seems right to assume that the tendency to lose water and salt, so often encountered in pyelonephritis, results in a dilution of the urine, and in some way protects the calculous kidneys from oxalate precipitation.

Abnormal endogenous oxalic acid formation, however, does not seem to be the only factor which determines the course of oxalosis. Both in the medical literature (Largiadér and Zollinger, 1960) and in the case reports above mentioned indications can be found that calcium metabolism is involved in a certain stage of the process. The occurrence of parathyroid hyperplasia in case 2 , together with the high serum phosphate level and marked acidosis in both cases, gives evidence of a secondary (renal) hyperparathyroidism with consequent calcium mobilization. The slightly lowered serum calcium is in accordance with this phenomenon. It is known that deposition of calcium (oxalate?) in the renal tubules and metastatic calcification of the arterial walls occurs in this condition. The possibility should therefore be considered that an enhanced activity of the parathyroid is also responsible for further renal damage in oxalosis.

In this connexion the symptoms of a defective circulation in the legs and feet, which we found in case 1 and less markedly in case 2, deserve attention. Richards (1951) mentioned ischaemic muscle pains in the extremities and even gangrene in some cases of secondary hyperparathyroidism. In both instances the defect may be explained by vascular deposition of calcium oxalate.

Although its significance is not yet clear, this similarity between the features of oxalosis and of secondary hyperparathyroidism should be stressed.

We are grateful to Mr. R. P. Mouton for the bacteriological determinations, and to Mr. C. J. M. de Groot of the Institute of Medical Radiology, Utrecht, for Figure $1 \mathbf{b}$.

\section{REFERENCES}

Brož, O., Štoví̌ek, Z., and Štěpán, I. (1957). Klin. Wschr., 35, 1042. Dérot, M., Legrain, M., Prunier, P., and Quénus, L. (1962). J. Urol. Néphrol., 68, 589.

Friedman, E. A., Greenberg, J. B., Merrill, J. P., and Dammin, G. J. (1962). Amer. J. Med., 32, 891.

Godwin, J. T., Fowler, F., Dempsey, E. F., and Henneman, P. H. (1958). New Engl. J. Med., 259, 1099.

Largiadér, F. (1960). Virchows Arch. Path. Anat., 333, 390.

, and Zollinger, H. U. (1960). Ibid., 333, 368.

Randerath, E., and Bohle, A. (1959). In Handbuch der allgemeiner Pathologie, Vol. V, part II, pp. 228-235. edited by F. Buechner, E. Letterer, and F. Roulet. Springer, Berlin.

Richards, D. G. B. (1951). Brit. med. J., 1, 167.

Scowen, E. F., Stansfeld, A. G., and Watts, R. W. E. (1959). J. Path. Bact., 77, 195.

Zollinger, H. U., and Rosenmund, H. (1952). Schweiz. med. Wschr., $82,1261$. 